OPEN ACCESS

Edited by:

Malcolm Ronald Starkey, Monash University, Australia

Reviewed by:

Cyril Seillet,

Walter and Eliza Hall Institute of

Medical Research, Australia

Lisa Anna Mielke,

Olivia Newton-John Cancer Research Institute, Australia

*Correspondence:

Kelly M. McNagny kelly@brc.ubc.ca

Specialty section:

This article was submitted to NK and Innate

Lymphoid Cell Biology,

a section of the journal

Frontiers in Immunology

Received: 15 March 2021

Accepted: 20 April 2021

Published: 06 May 2021

Citation:

Shin SB and MCNagny KM (2021) ILCYou in the Thymus: A Fresh Look at Innate Lymphoid Cell Development.

Front. Immunol. 12:681110. doi: 10.3389/fimmu.2021.681110

\section{ILC-You in the Thymus: A Fresh Look at Innate Lymphoid Cell Development}

\author{
Samuel B. Shin ${ }^{1,2}$ and Kelly M. McNagny ${ }^{2,3 *}$ \\ ${ }^{1}$ Department of Experimental Medicine, University of British Columbia, Vancouver, BC, Canada, ${ }^{2}$ School of Biomedical \\ Engineering, University of British Columbia, Vancouver, BC, Canada, ${ }^{3}$ Department of Medical Genetics, University of British \\ Columbia, Vancouver, BC, Canada
}

The discovery of innate lymphoid cells (ILCs) has revolutionized our understanding of innate immunity and immune cell interactions at epithelial barrier sites. Their presence and maintenance are critical for modulating immune homeostasis, responding to injury or infection, and repairing damaged tissues. To date, ILCs have been defined by a set of transcription factors, surface antigens and cytokines, and their functions resemble those of three major classes of helper T cell subsets, Th1, Th2 and Th17. Despite this, the lack of antigen-specific surface receptors and the notion that ILCs can develop in the absence of the thymic niche have clearly set them apart from the T-cell lineage and promulgated a dogma that ILCs develop directly from progenitors in the bone marrow. Interestingly however, emerging studies have challenged the BM-centric view of adult ILC development and suggest that ILCs could arise neonatally from developing $T$ cell progenitors. In this review, we discuss ILC development in parallel to T-cell development and summarize key findings that support a T-cell-centric view of ILC ontogeny.

\section{Keywords: T-cell development, innate lymphoid cell development, layered hematopoiesis, neonatal, fetal, origins} of lymphocytes

\section{INTRODUCTION}

While hints of innate type immune cell subsets, including NK cells and lymphoid tissue inducer (LTi) cells, were discovered as early as 1970s and early 2000s respectively $(1,2)$, a more detailed and full characterization of the innate lymphoid cell (ILC) family emerged in the late 2000s (3). Undoubtedly, their classification marks a formative breakthrough that changed our perception of the immune system and immune homeostasis (4-6). In just over a decade, ILCs were shown to be important in allergic disease, autoinflammation and immune tolerance $(7,8)$. Previous and ongoing studies have highlighted them as key drivers of inflammation and fibrosis in inflammatory bowel disease, inducers of chronic airway inflammation, and active players in other disorders such as obesity and cancer (9-14). In general, ILCs are tissue-resident and are triggered through relatively broad spectrum receptors for pathogens or inflammatory cues rather than specific-antigen receptors (BCRs or TCRs). Upon appropriate alarmin signaling, they orchestrate downstream responses by communicating with neighboring stromal and immune cells to adjust the cytokine microenvironment in a fashion that promotes protection, health and homeostasis at mucosal barrier sites $(5,15)$. In addition, they have also emerged as regulators of homeostasis and tissue repair in non-barrier organs (16). 
Molecularly, ILCs are extremely heterogenous but, for convenience, have been grouped into subsets that resemble the classification of $\mathrm{T}$ cells based on their surface marker, cytokine and transcription factor profiles during development and activation (ILC1/NK, ILC2 and ILC3/LTi) $(17,18)$. Thus, like type 1, 2 and 17 helper T cells, ILC1, 2 and 3 are categorized according to the class of immune response they invoke upon perturbation. ILC1s include conventional NK cells and "helper ILC1s" and are defined by the production of interferon $\gamma($ IFN- $\gamma)$ in response to IL-12, IL-15 and IL-18 (19). The transcription factor, T-bet, functions as their master regulator with Eomes being present in NK cells and a small subset of ILC1s $(20,21)$. ILC2s, on the other hand, depend on the expression of GATA3, and are responsible for generating type 2 cytokines such as IL-5, IL-9, IL-13 and amphiregulin upon stimulation by the alarmins, IL-25, IL-33 and TSLP $(12,22,23)$. Lastly, ILC3s are defined by production of IL-17 and IL-22 in response to IL-23 and IL-1 $\beta$ signaling and are maintained by the transcription factors ROR $\gamma \mathrm{t}$ and $\operatorname{ROR} \alpha(24,25)$. Within the ILC3 group, there also exists an LTi family that arises during embryogenesis and facilitate the formation of secondary lymphoid tissues (26). Broadly speaking, ILC1s are involved in the clearance of intracellular pathogens, ILC2s are associated with helminth infection and chronic airway inflammation in response to allergens (27), and ILC3s are predominantly implicated in gut immunity and responsible for establishing tolerance and mucus secretion (17).

Because ILCs closely resemble helper T cells, they are often regarded as the innate counterparts of Th1, Th2 and Th17 cells. Despite this, current dogma suggests that the ontogeny of ILCs and $\mathrm{T}$ cells are separate and distinct, and that the thymic microenvironment is dispensable for ILC maturation (19). This concept arose from three distinct observations made from seminal studies that identified ILCs and their function. First, unlike T cells, all subset of ILCs do not depend on the expression of surface antigen-specific T-cell receptors (TCR) for their development and activation (18). Therefore the thymus, the site which provides the appropriate niche for TCR gene rearrangements and signaling through TCR and other coreceptors, was not considered to be important in ILC biology. Second, they are present, expanded and functional in mice with profound lesions in T-cell development including Foxn ${ }^{n u / n u}$ (nude) and in $\mathrm{Rag}^{-/-}$mice (28). Lastly, the characterization of early ILC progenitors in the adult BM and their restricted T-cell potential as they differentiate downstream of common lymphoid progenitors (CLP) have left an impression that the unique microenvironment of the thymus is dispensable for ILC development (29-32). As a result, investigations of ILC development in adult animals have focused predominantly on the key progenitor populations originally described in the adult $\mathrm{BM}$, and the concept of ILCs arising during early T-cell development, until recently, has remained largely unexplored.

With the identification of BM ILC progenitors, the mapping of signaling pathways and factors that contribute to ILC development became the topic of intense investigation. Interestingly, these studies found that although ILCs do not undergo TCR-dependent development or activation, the factors required for their commitment and maturation are virtually indistinguishable from those found in T-cell development with the noteworthy exception of NFIL3 expression in early BM ILC progenitors $(18,32-34)$. Furthermore, recent reports have highlighted the ontogeny and presence of ILCs in embryonic/ neonatal thymi $(35,36)$, suggesting that the bifurcation of T- and ILC-driven lineages, at least during neonatal life, is at the committed T-cell progenitor stage in the thymus. Here, we revisit ILC development in the context of neonatal T-cell development with a focus on recent literature highlighting layered ontogeny of ILC2s and TCR gene rearrangements and propose a model that more closely aligns the development of ILC and $\mathrm{T}$-cell lineages during neonatal life.

\section{AN OVERVIEW OF THE BM MODEL OF ILC DEVELOPMENT}

The current framework of ILC development was built on the identification of $\mathrm{CXCR}^{+} \alpha$-lymphoid progenitors $(\alpha-\mathrm{LP})$, early innate lymphoid progenitors (EILP), common helper ILC progenitors (CHILP) and ILC precursors (ILCP) in the adult BM (Figure 1). These were discovered and classified through a series of differentiation assays and transcription factor analyses that determined whether these precursors could competently become either ILC1, ILC2 or ILC3 (37). Briefly, it is thought that ILC lineage commitment occurs at the level of CXCR $6^{+} \alpha$-LPs and EILPs. These progenitors are direct descendants of CLPs in that they retain both ILC and NK cell potential, but lack the ability to become functional $\mathrm{T}$ or $\mathrm{B}$ cells. Transcriptomic and protein analyses revealed that transcription factors NFIL3, TOX and TCF-1 (Tcf7) are critical in ILC lineage specification as they precede the expression of downstream ILC progenitor genes (29, $32,38)$. In contrast, CHILPs and ILCPs represent further restricted downstream progenitors that have lost the ability to form T, B and NK cells. CHILPs and ILCPs are defined by the expression of transcription factors Id2 and PLZF, which reaffirms their commitment to helper ILC subsets $(30,39)$. Subsequently, based on the upregulated expression of T-bet (ILC1), GATA3, ROR $\alpha$, Bcl11b (ILC2) and ROR $\gamma$ t (ILC3), the precursors become one of three mature ILC subsets (18) (Figure 1). Using this model as a foundation, later studies examined other possible sources of tissue-resident ILCs in adult and during embryonic development. Similar to the adult $\mathrm{BM}$, it was shown that ILC development occurs in the fetal liver from Id2, PLZF and Arginase-1 (Arg-1) expressing ILC progenitors $(40,41)$. Fetal ILC development contributes predominantly to the generation of $\mathrm{CD}^{+} \mathrm{LTi}$ cells and NKp46 ${ }^{+}$ILC3s which then migrate to the gut and guide Peyer's patch development (42). NK1.1 ${ }^{+}$ILC1 precursors are also found in the fetal liver. However, their gene expression signature resembles that of adult hepatic ILC1s suggesting that, perhaps, they represent liver-specific precursors that are longlived, maintained, and self-renewed after their genesis in early liver development $(43,44)$. To date, the exact timepoint in which ILC progenitors colonize the periphery is unclear. Surprisingly, 


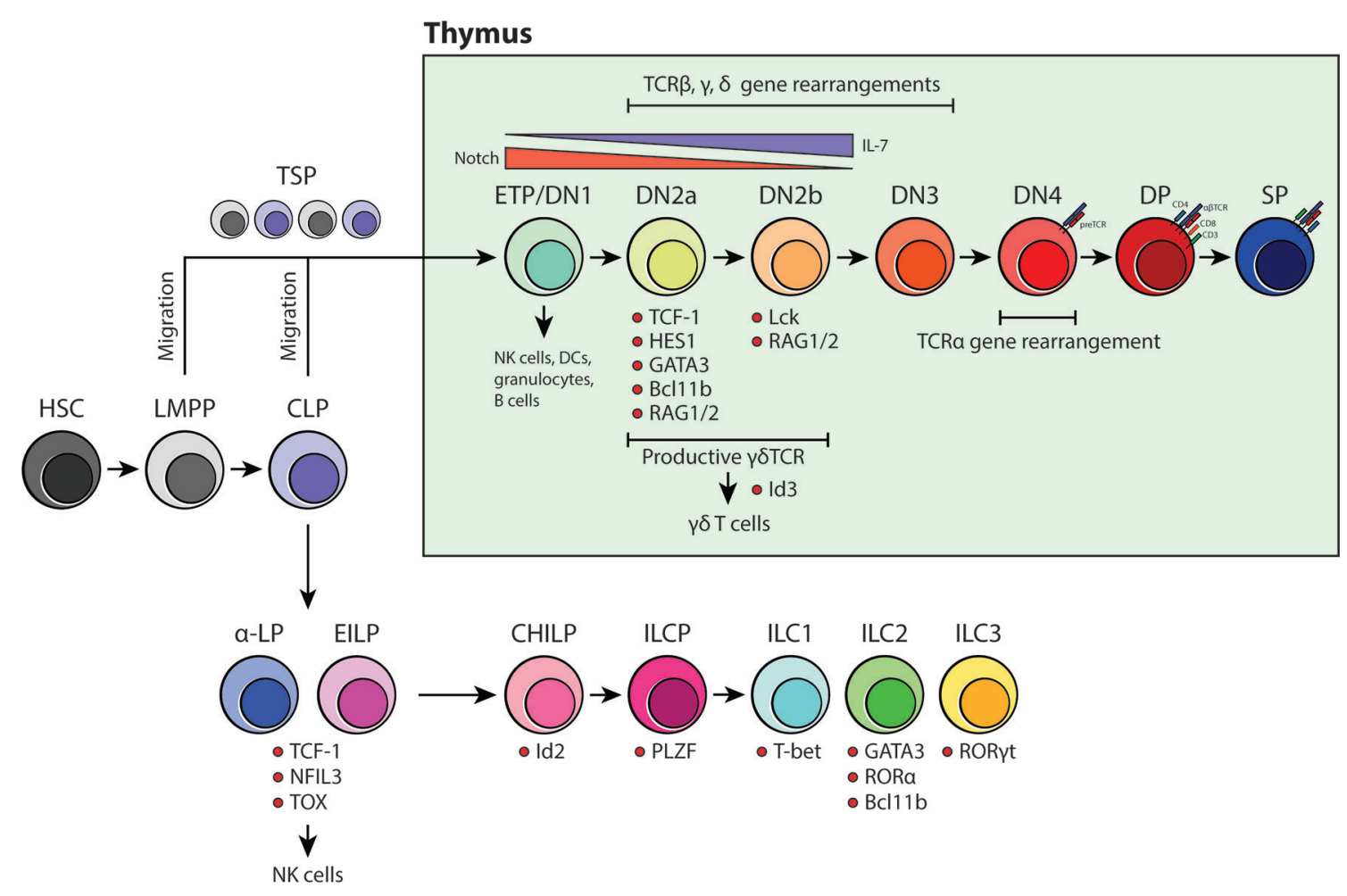

FIGURE 1 | An overview of BM-dependent ILC and thymus-dependent T-cell development. Current models for both ILC and T-cell development suggest that they are of distinct lineages and that the site for maturation do not overlap beyond the CLP stage. ILCs have been proposed to develop in the BM whereas committed T-cell progenitors undergo intense development processes that are heavily influenced by the thymic niche.

elegant recent parabiosis and pulse-label lineage tracing studies showed that the majority of tissue-resident ILC1, ILC2, ILC3 and LTi cells residing in the mucosal barrier tissues are not replenished through steady-state BM lymphopoiesis but instead self-renewed locally in their tissue of residence (44-47). Furthermore, tissue-resident lung $\mathrm{Il} 18 \mathrm{r}^{+}{ }^{+} \mathrm{ST} 2^{-}$ILC2 progenitors have been recently shown to produce ILC2s locally upon immune challenge and independent of de novo production of ILCs in the BM (48). These simple observations then call into question the concept and significance of BM ILC generation and its contribution to the peripheral ILC pool.

\section{NORMAL THYMIC DEVELOPMENT OF T CELLS}

In contrast to most other hematopoietic lineages, T-cell development is critically dependent on the ability of developing thymocytes to undergo a strict maturation process in the thymic microenvironment before colonizing the peripheral tissues (Figure 1). Originally, CLPs were thought to be the only branchpoint in which T-cell fate restriction occurs. However, with the discovery of lymphoid-primed multipotent progenitors (LMPP), the classical view of T-cell development was revised to include a secondary pathway that was independent of
CLPs (49). LMPPs are defined by their expression of the fms-like tyrosine kinase 3 (Flt3) and are positioned upstream of CLPs in the differentiation hierarchy $(50,51)$. Like CLPs, they are restricted to the $\mathrm{T}$-, $\mathrm{B}$-cell and $\mathrm{NK}$ cell lineage, but are different in that they retain the potential for granulocyte/ monocyte development. It has been shown that LMPPs are much more akin to ETPs in the thymus, suggesting that the thymus-seeding progenitor (TSP) pool includes both LMPPs and downstream CLPs lacking Ly6 ${ }^{-}$expression $(49,52)$. Once in the thymus, $\mathrm{CD}^{-} \mathrm{CD}^{-}$TSPs enter the double negative (DN) stage in T-cell specification. This stage is divided into four major compartments: DN1/ETP to DN4 (Figure 1). Depending on the differential expression of CD24, CD25, CD44 and CD117 (KIT) and the state of the TCR loci, developing DN thymocytes are classified as either DN1/ETP, DN2a, DN2b, DN3 or DN4 (49, 53). DN1 cells represent $0.01 \%$ of the total T-cell progenitors in the thymus and are surprisingly multipotent as they retain the ability to differentiate into cells of the myeloid and lymphoid lineages. However, upon arrival at the corticomedullary junction, Notch signaling induces a genetic program that secures their commitment to the T-cell fate and prepares them for TCR gene rearrangement (49). As these cells progress to the DN2 stage, they become localized within the subcapsular zone of the thymic cortex. Here, they begin rearranging their TCR $\beta, \gamma$ and $\delta$ loci via the activation of Rag1 and Rag2 genes. It is expected that DN2 
cells become more dependent on IL-7 produced by thymic epithelial cells (TEC) as it is vital for their proliferation, survival and differentiation (54). There are two subtypes of DN2 cells, DN2a and DN2b, and they are characterized based on the expression of lymphocyte-specific protein tyrosine kinase (Lck) and the ability to suppress NK, myeloid and dendritic cell (DC) potential. Although they are more restricted than DN1/ ETPs, DN2a cells are still relatively fluid in terms of their differentiation potential. This however, is lost as they continue through the process of TCR gene rearrangement and transition towards DN2b (55). At DN3, developing thymocytes extensively rearrange their DNA at the TCR $\beta, \gamma$ and $\delta$ loci and are selected for survival based on the expression of functional $\gamma \delta$ or preT $\alpha / \beta$ (preTCR) chains. $\gamma \delta$ TCR expression, along with transcription factor Id3, promotes $\gamma \delta$ T-cell development whereas preTCR expression guides the remaining DN3 cells to enter the DN4 stage. Once at the DN4 stage, thymocytes begin migrating back towards the medulla and initiate TCR $\alpha$ gene rearrangements upon preTCR signaling. After the formation of a functional $\alpha \beta T C R$, thymocytes then upregulate CD4 and CD8 co-receptors to become double positive (DP) thymocytes. From here, DP cells are positively selected for reactivity with $\mathrm{MHC}$, becoming either CD4 or CD8 single positive (SP) cells. Shortly thereafter, the surviving SP cells undergo negative selection against autoreactivity and become mature naïve $\mathrm{T}$ cells $(49,53,54)$ (Figure 1).

\section{ILCs ARE LONG LIVED TISSUE-RESIDENT CELLS IN ADULT AND COLONIZE TISSUES DURING FETAL/NEONATAL DEVELOPMENT}

The working model of adult hematopoiesis argues that the BM is responsible for generating and replenishing all blood and immune cells required for the lifetime an individual. Although this is true for some short-lived circulating leukocytes (56), it has become increasingly clear that tissue-resident cells such ILCs, macrophages, mast cell subsets and $\gamma \delta \mathrm{T}$ cells persist throughout life and, for the most part, expand and contract locally in their tissue of residence, largely independent of hematopoietic activity in the BM (45,57-60). As outlined in Elsaid et al. (61), the developmental pathways for most tissue-resident cells do not fit the rudimentary model of adult hematopoiesis, but instead, follow a highly conserved and layered approach during ontogeny. These cells arise in distinct waves in coordination with tissue development, thus accounting for both the spatial and temporal aspects of embryogenesis. It is thought that highly coordinated programs and interactions between the stromal and immune cells facilitate tissue development, in addition to providing early immune protection specific to a given tissue type (61).

Considering the fact that BM ILC progenitors provide minimal contributions to tissue-resident ILC pools, it stands to reason that tissue-resident ILCs perhaps colonize during early stages in ontogeny rather than constantly being restored through BM lymphopoiesis. Intriguingly, the idea of layered ontogeny in ILC development has recently been explored in a lineage tracing study that closely monitored ILC2 development and turnover (47). Through elegant pulse-labeling of putative BM and fetal ILC precursors (Id $2^{+}$and Arg- $1^{+}$respectively) $(30,62)$, this group showed that development of ILC2s is temporally controlled and that they follow the model of layered lymphopoiesis similar to the one described in early macrophage development. These findings argue that ILC2s rapidly colonize peripheral tissues during the first week or two of postnatal life in mice and at a time when the bone marrow (BM) is still establishing itself as the sole source of hematopoietic progenitor activity. Strikingly, this study also concludes that once they establish residence in peripheral tissues, ILC2s turn over very slowly within the specific peripheral tissue microenvironments. This includes BM ILC2s, which appears to turnover with a kinetics of weeks to months rather than days. Thus, the evidence to suggest that BM ILC2s seed peripheral tissues to any large degree is increasingly scant and it is likely that the ILC2s present within the BM represent tissue-resident cells with tissue-specific function (Schneider et al., 2019). Indeed, a subsequent fate-mapping study using polychromic reporter mice expressing Id2, Bcl11b, GATA3, ROR $\alpha$ and ROR $\gamma \mathrm{t}$ revealed codifferentiation of ILCs and developing thymocytes in embryonic thymi, strengthening the concept that ILCs develop early in life parallel to early T-cell development (36).

\section{TCR GENE REARRANGEMENTS IN ILCs}

$\mathrm{V}(\mathrm{D}) \mathrm{J}$ recombination at the TCR loci is an extraordinary process reserved for committed thymocytes at their DN stage. It is thought to occur in sequence as $\mathrm{DN}$ cells progress towards more committed DP state. TCR gene expression, as a unique hallmark of T-cell development, has hinted at a strikingly close relationship between ILCs and T cells in the past with both EILPs and ILCPs expressing high levels of sterile TCR transcripts even though they were originally identified in the adult BM (63). In order to concretely address whether ILCs stem from embryonic/ neonatal T-cell development, we recently performed detailed genetic analyses of all TCR loci in mature tissue-resident ILCs. Single-cell analyses of cecal ILC1, 2 and $3 \mathrm{~s}$ and lung ILC2s showed abundant expression of TCR constant region transcripts. Specifically, C $\beta$ transcripts are expressed in all ILC subsets while $\mathrm{C} \alpha, \gamma$ and $\delta$ transcript levels are more closely associated with specific ILC subsets. Subsequent in-depth genomic analyses revealed that although lung ILC2s do not show evidence of DNA rearrangements at the TCR $\beta$ loci, they exhibit clear evidence of rearrangements at their TCR $\gamma$ loci in a pattern that is strikingly similar to mature $\mathrm{V} \gamma 2^{+} \gamma \delta \mathrm{T}$ cells. In addition, qPCR analysis shows that at least one of the TCR $\delta$ alleles is frequently deleted. Lastly, when sequenced, $\mathrm{V} \gamma 2$-J $\gamma 1$ rearrangements were found to be largely out-of-frame, thus precluding their ability to express a functional TCR $\gamma$ subunit even if this locus was actively transcribed and translated (64). 
The detailed characterization of TCR gene rearrangements performed in our study offers a fascinating window into the life history of ILC2s. The preferential expression of TCR $\gamma$ constant regions and preponderance of non-productive TCR $\gamma$ and $\delta$ gene rearrangements without the VDJ recombination of the TCR $\beta$ locus suggest the possibility that ILC2s may abortively arise from DN2-DN3 transition stage during $\gamma \delta$ T-cell development. As reviewed in Spidale et al. (59), the development of tissue-resident $\gamma \delta \mathrm{T}$ cells occurs early in life in a time-sensitive manner. Unlike adult $\alpha \beta$ T cells, $\gamma \delta$ T cells emerge in progressive waves that are defined by the specific gene usage of $\mathrm{V} \gamma$ and $\mathrm{V} \delta$ segments during fetal/neonatal development (58). ${\mathrm{V} \gamma 3^{+}} \delta \mathrm{T}$ cells (also known as DETCs) are the first $\mathrm{T}$ cell subset to arise from the fetal liver during embryogenesis. They preferentially migrate to the epidermis and provide early immunity in developing skin. Subsequent $\gamma \delta \mathrm{T}$ cells that follow this vanguard wave of DETCs are ${\mathrm{V} \gamma 4^{+}}^{+}$and $\mathrm{V} \gamma 2^{+} \gamma \delta \mathrm{T}$ cells. $\mathrm{V} \gamma 4^{+} \gamma \delta \mathrm{T}$ cells seed non-lymphoid tissue sites such as the uterus, lung, adipose tissue and skin dermis during late fetal development while $\mathrm{V} \gamma 2^{+} \gamma \delta \mathrm{T}$ cells appear during the late fetal/neonatal stage, colonizing various mucosal and non-mucosal sites (59). In line with the layered model of ILC-genesis, it is possible that abortive V $\gamma 2$-J $\gamma 1$ locus rearrangements in tissue-resident ILC2s represent an ontogeneologic relic of "failed" $\mathrm{V} \gamma 2^{+} \gamma \delta$ T-cell development (Figure 2). When viewed in the context the aforementioned neonatal lineage tracing experiments (47) and the presence of ILCs in the embryonic thymus and their dependence on early T-cell transcription factors (36), a compelling case emerges for the development of ILCs from abortive T-cell development and as an offshoot from neonatal T-cell progenitors.

In addition to ILC2s, it is noteworthy that earlier studies showed the TCR loci are also frequently rearranged in NK cells. Comprehensive genomic analyses of adult and neonatal splenic NK cells revealed that the TCR $\gamma$ locus is rearranged while TCR $\beta$ locus maintains its germline configuration. Intriguingly, unlike ILC2s, NK cells were reported to express rearranged TCR $\gamma$ transcripts; however, the sequencing data exhibited a variable degree of productive rearrangements despite being isolated from mRNA products. Minimal TCR $\delta$ locus rearrangements (V $\delta 4$ J $\delta 1$ ) were detected and only in neonatal NK cells, suggesting that similar to ILC2s, at least one allele could have been deleted due to an abortive gene rearrangement event at the TCR $\alpha / \delta$ loci (65).

Further evidence for TCR gene rearrangements in other ILC subsets has recently been demonstrated in human studies through sophisticated single-cell transcriptome analyses that revealed gene expression patterns associated with tissueresidency and migration in human ILCs (66). In this report, blood ILC1s $\left(\mathrm{EOMES}^{-/+}\right.$) are shown to uphold the expression of T-cell related-genes such as CD3, CD4, CD5, CD6, CD27, LEF1. As such, the group investigated whether these cells and other ILC subsets express rearranged TCR transcripts, despite lacking surface TCRs. They showed that blood EOMES ${ }^{+}$ILC1s express rearranged $\alpha \beta$ chains and putative blood EOMES ${ }^{-}$ILC1s exhibit $^{-}$ rearrangements in all four TCR chains. Within this pool, ILC1s with rearranged $\delta / \gamma$ transcripts associated with $I k z f 2$ expression while ILC1s with rearranged $\alpha / \beta$ transcripts clustered closely

\section{Thymus}

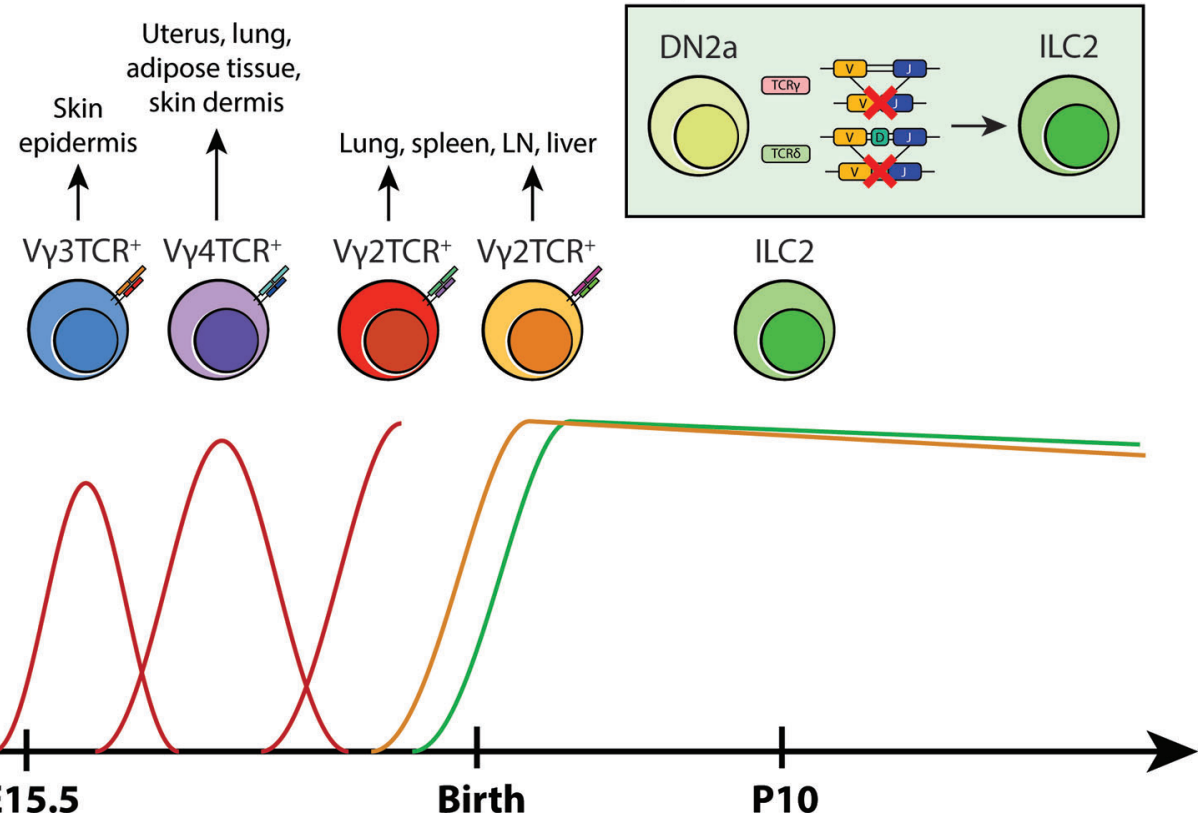

FIGURE 2 | A new model for layered ontogeny of ILC2s along with fetal and postnatal waves of $\gamma \delta$ T cells. Like most tissue-resident cells, the developmental timepoint in which ILC2s arise and colonize tissues coincides with $\gamma \delta$ T cells early in life (based on layered ontogeny in B6 mice). Taken together with TCR locus sequence tracing data and pulse-labeling lineage tracing studies, it is highly likely that tissue-resident ILC2s arise perinatally from developing DN2s that have ineffectively rearranged their $\gamma / \delta$ loci, rather than from progenitors in the BM. These cells then take up residence at their designated tissue sites and self-renew locally. 
with $\mathrm{CXCR}^{+}$Th1 cells (66). These observations suggest that ILC1s are more akin to $\mathrm{CD} 4^{+}$and $\mathrm{CD}^{+} \mathrm{T}$ cells and that in their lifetime, they have undergone a maturation process in the thymus. Although it is noteworthy that, these authors failed to detect rearranged TCR $\gamma$ chain expression in human ILC2s, it is also important to bear in mind that these studies only evaluated TCR transcripts rather than the genomic loci. Indeed, in our previous studies of murine ILC2 genomic loci and transcripts, we found that the rearranged loci are transcriptionally silent in murine ILC2s as well, potentially reflecting an attempt to silence alleles that have failed productive in-frame rearrangement; a process that naturally occurs in developing thymocytes. With this in mind, it would be of interest to now evaluate genomic TCR loci in human ILC subsets. Although human and murine ILC/T-cell biology exhibit significant differences, the use of TCR gene rearrangements as an indelible mark of the lineage of origin in both of these studies points to a thymic origin of the tissueresident ILCs.

\section{NOTCH SIGNALING, THE INITIAL FATE DETERMINATOR IN THE THYMUS}

In addition to abortive $\mathrm{V}(\mathrm{D}) \mathrm{J}$ recombination, limited Notch signaling in the thymic microenvironment may also determine whether thymocytes continue developing as $\mathrm{T}$ cells or shunt away from the T-cell lineage and into ILC lineages. Notch activity was discovered in the early $20^{\text {th }}$ century from strains of Drosophila that exhibited serrated "notched" wings (67). Its signaling pathway is evolutionarily conserved and is imperative for regulating cell fate decisions, survival, proliferation and niche formation (68). In the context of T-cell development, Notch1 and its ligand, Delta-like 4 (DLL4), serve as an essential checkpoint signal that imprints T-cell identity in TSPs entering the thymus. Their signaling is mediated by direct cell-cell interaction between TSPs and TECs and promotes the acquisition of $\mathrm{T}$-cell fate by upregulating $\mathrm{T}$-cell specific genes while gradually repressing myeloid and B-cell potential $(49,69)$. Upon interaction, a series of proteolytic cleavage events release the cytoplasmic domain of Notch, which then binds to recombination binding protein-J (RBP-J) in the nucleus and activates transcription of genes associated with $\mathrm{T}$-cell development including Tcf7, Hes1, Gata3 and Bcl11b (54, 69, 70). Loss-of-function studies of Notch1 and Cre-mediated deletion of DLL4 revealed aberrant proliferation of B cells in the thymus, and argues that their presence is indeed necessary for T-cell commitment (49). In contrast, the importance of Notch signaling in ILC development has been quite controversial. Deletion of RBP-JK in hematopoietic cells leads to a noticeable reduction in the frequency of lamina propria NKp46 ${ }^{+}$ILC3, but not CD4 ${ }^{+}$LTi-like cells $(71,72)$. Moreover, culturing EILPs on OP9-DLL1 stroma results in enhanced generation of ILC2s, yet the development of all ILC subsets is unaffected in the absence of Notch signaling (29). Lastly, multiple groups have concluded that committed ILC progenitors and precursors have diminished dependency on Notch $(29,31,73)$, thus creating the notion that its signaling is dispensable in ILC development. More recently however, an in vitro assay performed using a Tet-inducible cell system, which allows for fine-tuning of DLL1 and DLL4 expression under doxycyclin, revealed that the strength and duration of Notch signaling influences the development of different ILC subsets. In this study, CLPs that were exposed to robust Notch-DLL signaling differentiated predominantly into T cells, LTi cells and ILC3s, whereas those receiving intermediate signaling preferentially became ILC1s/NK cells and ILC2s. Expectedly, CLPs with minimal to no Notch signaling led to B-cell differentiation (Figure 3). The same study also showed that specific deletion of DLL4 on TECs results in an abnormal expansion of ILC2 in the thymus (38), suggesting that the gradient of Notch signaling may influence ILC fate in the thymic microenvironment.

Notch signaling is not binary, but rather it is dose- and timedependent during ontogeny and in cell fate decisions (68). It is widely known that TSPs/ETPs are multipotent, and that T-cell potential is acquired progressively through DN to DP stage. Considering the fact that Notch signaling is facilitated by cell-cell interaction, it is highly likely that the size of initial thymic niche for ETPs is limited. Therefore, the degree and duration of Notch signaling would vary from cell to cell, leaving the option for other lineages to appear in the embryonic/postnatal thymus similar to the ones observed in the dose-dependent in vitro system (Figure 3). Addressing the redundancy of Notch in later ILC progenitors requires careful consideration of its unique purpose. Notch and its ligand interaction are often described in the context of development and regulation of cell fates. In both Tcell and ILC development, Notch establishes T-cell and ILC identity through upregulation of TCF-1 and its related transcription factors. As DN2 cells mature into DN3 cells, their dependency on Notch signaling decreases, eventually becoming redundant (74). Since a similar behavior is observed in downstream ILC progenitors, it is possible that TCF- ${ }^{+}$EILPs and CHILPs are already committed and downstream of developing thymocytes that share the same hierarchical level as DN3 cells in the differentiation hierarchy.

\section{E-Id PROTEINS AND Bcl11b DETERMINE THYMOCYTE FATE}

The transcription factors involved in positive and negative regulation of ILC differentiation have been discussed in great detail in other reviews $(19,69,75)$. Emerging studies have highlighted the fact that differential expression of factors associated with T-cell development, HES1, TCF1 and GATA3, ROR $\alpha, E$ and Id proteins, and Bcl11b, are all critical for ILC maturation (19, 36, 76-78). Among these, EId proteins and Bcl11b are especially interesting because they have been shown to play a role in inducing ILC development in the thymus. E proteins are under the class I basic helix-loophelix (bHLH) family of transcription factors that are historically described in early $\mathrm{T}$-cell lineage commitment and specification in coordination with Notch signaling. They form 


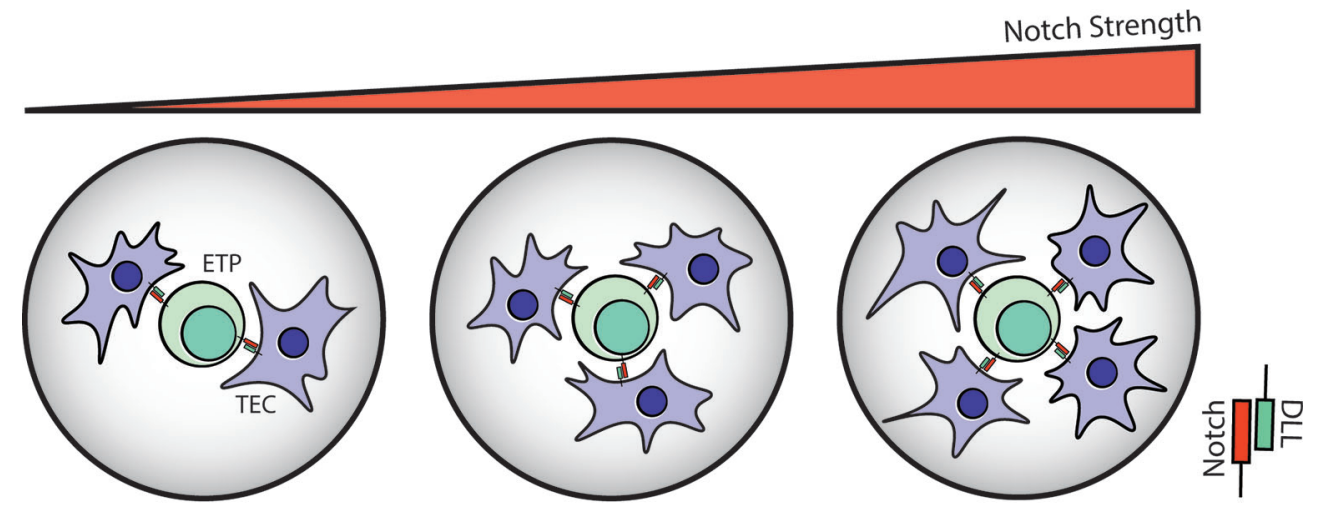

Thymus Corticomedullary Junction
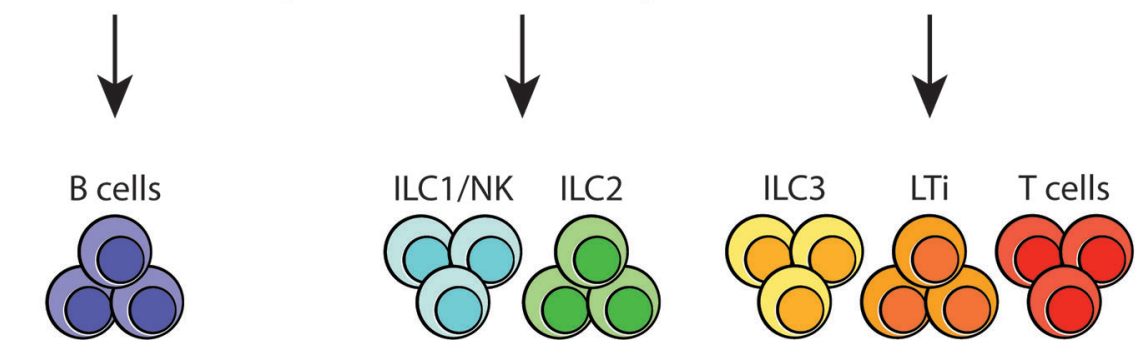

FIGURE 3 | Notch signaling at the thymus corticomedullary junction may determine T-cell/ILC fate. Notch signaling is mediated through direct cell-cell contact in the thymus; therefore, the number of TECs interacting with TSPS/ETPs at the corticomedullary junction will vary depending on cell position and niche availability. Based on the observations from in vitro assays, it is highly likely that ETPs that receive zero to low Notch-DLL interaction will differentiate into B cells. In contrast, strong Notch signaling will guide ETPs towards the T-cell and ILC3/LTi lineages while intermediate Notch signaling will result in ILC1/NK and ILC2 commitment during fetal and postnatal periods.

homo- or heterodimers (e.g., E2A-HEB) with other bHLH or HLH proteins, which then turns on the T-cell-specific program in developing thymocytes. E protein function is regulated by class IV HLH family inhibitor of DNA binding (Id) factors. Id proteins lack the DNA binding domain; thus, they sequester E protein function by forming a heterodimer complex that cannot bind to DNA (69). Intriguingly, hindering the activity of E proteins by deleting E2A and HEB or ectopically expressing Id 1 or Id 2 blocks the generation of functional $\mathrm{T}$ cells, and instead promotes ILC2 proliferation in adult thymi $(76,79,80)$. Furthermore, fetal ETPs lacking E2A and HEB in vitro can also generate ILC1- and ILC3-like cells (76); therefore, it is highly likely that the strength of Notch signaling, and E-Id protein levels may influence ETP fate in the thymus (Figure 4). Bcl11b, on the other hand, belongs to a family of Kruppel-like $\mathrm{C}_{2} \mathrm{H}_{2}$ type zinc finger transcription factors and is expressed in late DN2a thymocytes and essential for DN2-DN3 transition in T-cell development (69, 81). Bcl11b-deficiency causes arrest of $\mathrm{T}$ cells at the DN2a stage and, fascinatingly, allows aberrant differentiation of $\mathrm{NKp} 46^{+}$ ILC1/NK cells and myeloid cells in the thymus $(82,83)$. Bcl11b has also been implicated ILC2 biology and development. It is widely accepted that Bcl11b is important for overall ILC2 maintenance and function; however, in the original study that used heterozygous germline knockout and conditional knockout of Bcl11b, only the ST2 ${ }^{+}$BM ILC2 compartment was reduced upon Bcl11b deletion. Surprisingly, the frequency of lung-resident $\mathrm{ST}_{2}{ }^{+}$ILC2s was not affected by this genetic manipulation, but rather there was an incredible increase in the KLRG1 ${ }^{+}$ILC2 population (84). It would be extremely interesting to revisit these transgenic mice models and examine their thymus-residing cells to determine if there is an abnormal expansion of KLRG1 ${ }^{+}$ILC2s or perhaps other ILC subsets in the thymus through high fidelity single-cell sequencing. Considering this and the evidence for layered ontogeny of ILCs, it is quite possible that the origin of BM ILC2s and lung ILC2s is completely independent of each other and that E-Id proteins and Bcl11b may be the transcriptional checkpoints that initiate reprogramming of $\mathrm{T}$ cells that have neither received adequate Notch signaling nor undergone productive TCR gene rearrangements (Figure 4).

\section{ADDRESSING NORMAL DEVELOPMENT OF ILCS IN T-CELL KNOCKOUT MODELS}

The presence of functional ILC subsets in mice with genetic lesions in T-cell development raises an interesting conundrum because if ILCs are indeed associated with T-cell development, one might predict there would be a reduction in their frequency upon interfering with thymocyte maturation. In contrast, earlier characterization of ILCs has indicated that ILCs can develop and 


\section{Thymus}

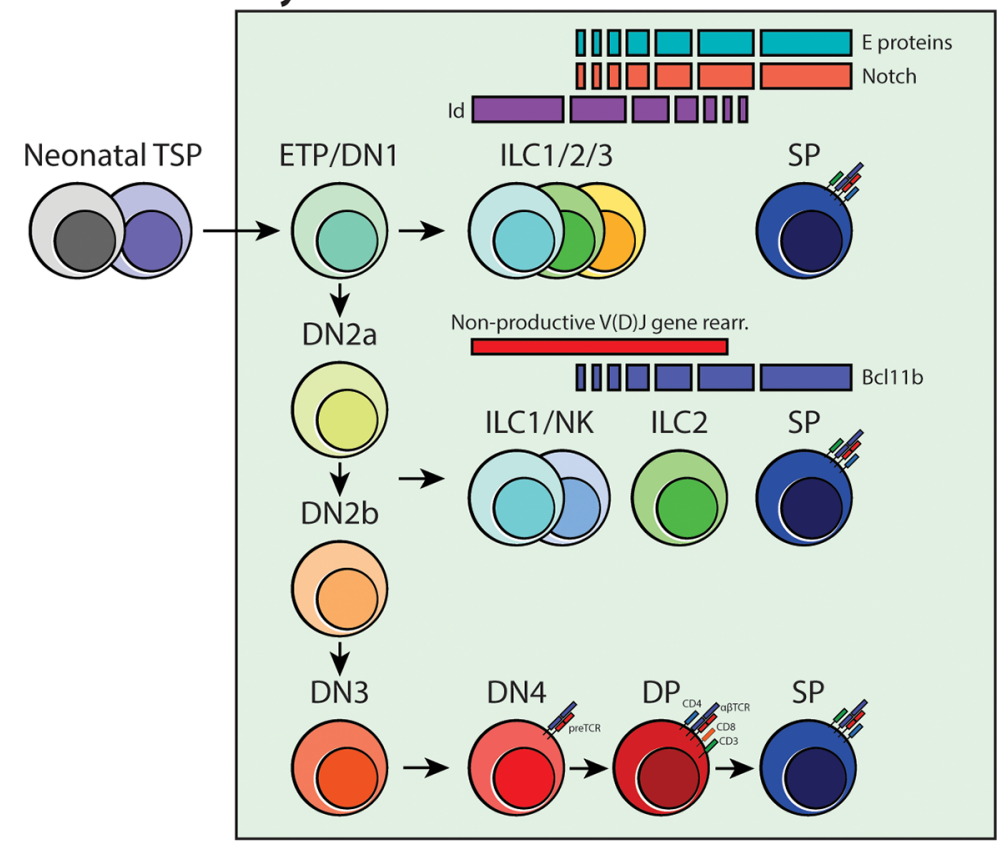

Non-lymphoid organs

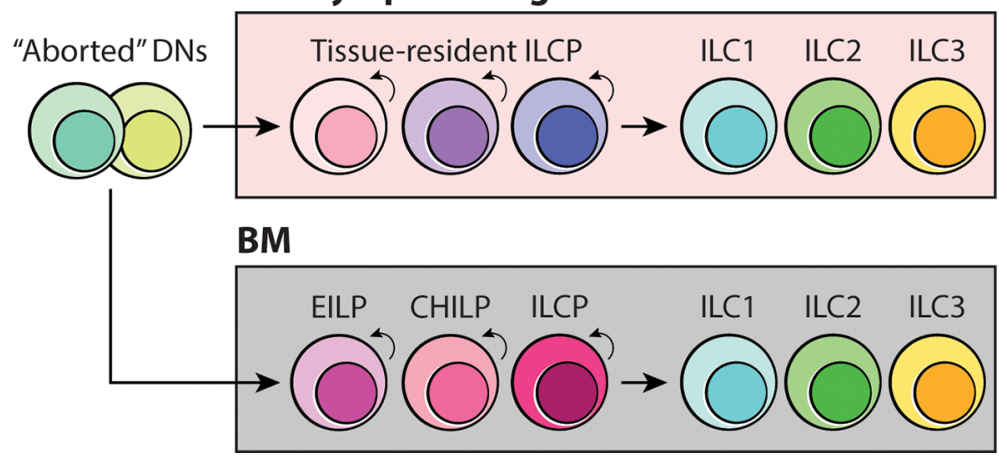

FIGURE 4 | Schematic of ILC development in coordination with thymocyte specification and maturation. As early T-cell progenitors are known to be multipotent, we propose that the branchpoint in which ILC differentiation occurs is at the DN1/ETP and DN2-DN3 transition stage. Depending on the status of the TCR loci, strength of Notch signaling and activities of E-Id proteins and Bcl11b, developing thymocytes may acquire innate-like properties and give rise to one of three ILC subsets. Furthermore, we suggest that tissue-resident ILC progenitors, including the BM, originate from failed T-cell development and locally maintain the mature ILC pool.

function normally in $\mathrm{Rag}^{-/-}$and nude mice, thus highlighting them as distinct subsets, independent of the T-cell lineage (85). With the evidence of non-productive TCR rearrangement, however, it is now critical to revisit this hypothesis and reevaluate it from the perspective of abortive T-cell development. In maturing thymocytes, RAG genes are typically expressed during the DN2-DN3 transition (49) (Figure 1). Therefore, without active RAG1 or RAG2 proteins, thymocytes cannot rearrange their TCR loci and progress further into latter stages of T-cell development (86-88). Taken together with the fact that pre-DN3 cells are multipotent, there is room for Rag-deficient ETPs and DN2a cells to shunt away from the T-cell lineage and immediately choose the innate cell fate as part of a salvage mechanism. Indeed, our characterization of ILC2s in $\mathrm{Rag}^{-/-}$ mice revealed that there is a heightened frequency of ILC2s in the thymus, indicating active generation of ILC2s upon blocking TCR gene rearrangements. Likewise, other studies have also characterized the heterogeneous populations of DN cells in RAG mutants containing putative NK cells (89), and suggesting that this pathway may apply to other ILC subsets. Similar to RAG mutants, the mature T-cell population is also substantially decreased in nude mice carrying null mutations of the forkhead transcription factor (FOXN1), which is essential for TEC differentiation during development (90). The nude mouse vestigial thymic microenvironment is detrimental for early $\mathrm{T}$-cell progenitors as it cannot provide sufficient Notch signaling for their specification and survival. Considering the evidence of dose-dependent Notch signaling in determining cell fate, it is 
highly likely that all T-cell progenitors are co-opted into the ILC fate program immediately after entering this non-functional thymic niche. This would increase the total frequency of ILCs in the peripheral tissues, and certainly, previous studies have observed heighten ILC counts at various barrier sites $(91,92)$. In future studies, it would be extremely interesting to purposefully disrupt TCR gene rearrangement at specific stages in development and investigate whether this influences the total number of ILCs in the periphery.

\section{FUNCTIONAL SIGNIFICANCE OF BM ILCs}

The vast majority of ILCs within the BM are affiliated with the ILC2 subset. Given the evidence that ILCs can develop neonatally from thymic precursors and become tissue-resident thereafter, the functional significance of BM ILC2s then comes into question. Likewise, the fact that these cells show a remarkably slow turnover (47) would argue against them serving as a precursor pool for peripheral ILCs and might instead suggest that, like peripheral ILCs, these cells fulfill an important tissueresident function. Consistent with this observation, it has been shown that self-renewal and maintenance of ILCs is facilitated by a pre-existing pool of tissue-resident ILCPs under inflammatory conditions $(45,48)$. Specifically, during the acute phase of Nippostrongylus brasiliensis helminth infection, ILC2s in the lung, gut and mesenteric lymph node proliferate locally without significant contribution from the BM $(45,47,93)$. The signs of recruitment and redistribution of ILC2s from other tissues including the BM only begin to appear after day 15 postinfection where the acute inflammatory conditions turn chronic and overt $(45,93,94)$. Recent studies have shown that their contribution is rather minor $(<10 \%)$ and that immature Il18r1 expressing BM ILCPs are responsible for seeding BM-derived ILC2s in the lung to generate the full phenotypic spectrum of ILC2s $(47,93)$. Indeed, there is a clear precedent for a selective BM-resident function for several mature hematopoietic lineages. Macrophage-like osteoclasts, for example, play a key role in bone remodeling and, together with osteoblasts regulate bone homeostasis (95). Similarly, the BM serves as a long-term reservoir and archive for antigen-specific, antibody-secreting plasma cells and possibly a unique population of isotypeswitched, affinity-mature memory B cells that could be called into service upon reinfection with specific pathogens $(96,97)$. With these examples in mind, it is worth considering a BM specific role for resident ILC2s. Intriguingly, several studies have suggested that BM ILC2s can, in fact, play key roles in stimulating eosinophilopoiesis in response to system Th2 inflammatory insults $(98,99)$. Likewise, recent studies suggest that through secretion of GM-CSF ILC2s can stimulate the recovery of $\mathrm{BM}$ hematopoiesis in response severe chemically induced stress (100). In aggregate, these studies suggest that, like there peripheral tissue counterparts, BM ILC2s may have colonized this tissue early in development and serve a tissueresident purpose thereafter. Taken together with previous TCR gene rearrangement data, it will now be important to test whether these cells, too, show genetic marks of deviation from early thymic progenitors.

\section{CONCLUDING REMARKS}

The recent discovery of ILCs has been transformative in our understanding of the development of finally orchestrated and appropriate immune responses to the appropriate pathogens and in bridging the division of labor between innate and adaptive immune responses. More recently, their functional significance has been expanded to include roles in non-barrier organs and key roles in tissue and organ homeostasis and repair. Despite this attention and these insights, a deep understanding of their ontogeny and development has lagged behind. Accumulating evidence now suggests remarkable conservation of molecular, transcriptional, and developmental parallels between these cells and neonatal $\mathrm{T}$ cells and, indeed, that in some instances these cells can develop from $\mathrm{T}$ cells that have failed to appropriately rearrange their antigen specific receptors. Studies of layered ontogeny of T cells and ILCs point towards the fact that longlived, tissue-resident ILCs are likely to be thymus-derived and that during steady-state or mild immune challenge, they expand and respond appropriately to remaining inflammation. However, in hematopoietic crisis, for example chronic inflammation, complete hematopoietic ablation, sepsis, or severe viral infections, BM stem cell derived ILCs may also be called into service and enter the peripheral niches to support the existing pool of tissue-resident ILC subsets. Certainly, future studies are needed to further clarify the relative contributions of these pools, their lineage relationships and whether they can be harnessed for improved treatment of clinical disease.

\section{AUTHOR CONTRIBUTIONS}

SBS and KMM wrote the manuscript and SBS designed the figures. All authors contributed to the article and approved the submitted version.

\section{FUNDING}

This work was funded by grant numbers PJT-148681 and PJT156235 from the Canadian Institutes of Health Research (CIHR). SBS was supported by an AllerGen Network Centre of Excellence and CIHR Frederick Banting \& Charles Best Canada Graduate Scholarship-Master's Program (CGS-M) Scholarship.

\section{ACKNOWLEDGMENTS}

We thank Jessica Cait for providing us with an original title for this review. 


\section{REFERENCES}

1. Kiessling R, Klein E, Pross H, Wigzell H. "Natural" Killer Cells in the Mouse. II. Cytotoxic Cells With Specificity for Mouse Moloney Leukemia Cells. Characteristics of the Killer Cell. Eur J Immunol (1975) 5(2):117-21. doi: 10.1002/eji.1830050209

2. Mebius RE, Rennert P, Weissman IL. Developing Lymph Nodes Collect CD4 +CD3- Ltbeta+ Cells That can Differentiate to APC, NK Cells, and Follicular Cells But Not T or B Cells. Immunity (1997) 7(4):493-504. doi: 10.1016/ s1074-7613(00)80371-4

3. Spits H, Di Santo JP. The Expanding Family of Innate Lymphoid Cells: Regulators and Effectors of Immunity and Tissue Remodeling. Nat Immunol (2011) 12(1):21-7. doi: 10.1038/ni.1962

4. Sonnenberg GF, Artis D. Innate Lymphoid Cell Interactions With Microbiota: Implications for Intestinal Health and Disease. Immunity (2012) 37(4):60110. doi: 10.1016/j.immuni.2012.10.003

5. Robinette ML, Colonna M. Innate Lymphoid Cells and the MHC. HLA (2016) 87(1):5-11. doi: 10.1111/tan.12723

6. Vivier E, van de Pavert SA, Cooper MD, Belz GT. The Evolution of Innate Lymphoid Cells. Nat Immunol (2016) 17(7):790-4. doi: 10.1038/ni.3459

7. Mohammadi H, Sharafkandi N, Hemmatzadeh M, Azizi G, Karimi M, JadidiNiaragh F, et al. The Role of Innate Lymphoid Cells in Health and Disease. J Cell Physiol (2018) 233(6):4512-29. doi: 10.1002/jcp.26250

8. Licona-Limon P, Kim LK, Palm NW, Flavell RA. TH2, Allergy and Group 2 Innate Lymphoid Cells. Nat Immunol (2013) 14(6):536-42. doi: 10.1038/ ni.2617

9. Gold MJ, Antignano F, Halim TY, Hirota JA, Blanchet MR, Zaph C, et al. Group 2 Innate Lymphoid Cells Facilitate Sensitization to Local, But Not Systemic, TH2-inducing Allergen Exposures. J Allergy Clin Immunol (2014) 133(4):1142-8. doi: 10.1016/j.jaci.2014.02.033

10. Lo BC, Gold MJ, Hughes MR, Antignano F, Valdez Y, Zaph C, et al. The Orphan Nuclear Receptor RORalpha and Group 3 Innate Lymphoid Cells Drive Fibrosis in a Mouse Model of Crohn's Disease. Sci Immunol (2016) 1(3): eaaf8864. doi: 10.1126/sciimmunol.aaf8864

11. Ebbo M, Crinier A, Vely F, Vivier E. Innate Lymphoid Cells: Major Players in Inflammatory Diseases. Nat Rev Immunol (2017) 17(11):665-78. doi: 10.1038/ nri.2017.86

12. Halim TY, Krauss RH, Sun AC, Takei F. Lung Natural Helper Cells are a Critical Source of Th2 Cell-Type Cytokines in Protease Allergen-Induced Airway Inflammation. Immunity (2012) 36(3):451-63. doi: 10.1016/j.immuni. 2011.12.020

13. Bruchard M, Ghiringhelli F. Deciphering the Roles of Innate Lymphoid Cells in Cancer. Front Immunol (2019) 10:656. doi: 10.3389/fimmu. 2019.00656

14. Wang H, Shen L, Sun X, Liu F, Feng W, Jiang C, et al. Adipose Group 1 Innate Lymphoid Cells Promote Adipose Tissue Fibrosis and Diabetes in Obesity. Nat Commun (2019) 10(1):3254. doi: 10.1038/s41467-019-11270-1

15. Withers DR. Innate Lymphoid Cell Regulation of Adaptive Immunity. Immunology (2016) 149(2):123-30. doi: 10.1111/imm.12639

16. Messing M, Jan-Abu SC, McNagny K. Group 2 Innate Lymphoid Cells: Central Players in a Recurring Theme of Repair and Regeneration. Int J Mol Sci (2020) 21(4):1350. doi: 10.3390/ijms21041350

17. Panda SK, Colonna M. Innate Lymphoid Cells in Mucosal Immunity. Front Immunol (2019) 10:861. doi: 10.3389/fimmu.2019.00861

18. Cherrier DE, Serafini N, Di Santo JP. Innate Lymphoid Cell Development: A T Cell Perspective. Immunity (2018) 48(6):1091-103. doi: 10.1016/j.immuni. 2018.05.010

19. Diefenbach A, Colonna M, Koyasu S. Development, Differentiation, and Diversity of Innate Lymphoid Cells. Immunity (2014) 41(3):354-65. doi: 10.1016/j.immuni.2014.09.005

20. Fuchs A. ILC1s in Tissue Inflammation and Infection. Front Immunol (2016) 7:104. doi: 10.3389/fimmu.2016.00104

21. Fuchs A, Vermi W, Lee JS, Lonardi S, Gilfillan S, Newberry RD, et al. Intraepithelial Type 1 Innate Lymphoid Cells are a Unique Subset of IL-12and IL-15-responsive IFN-Gamma-Producing Cells. Immunity (2013) 38 (4):769-81. doi: 10.1016/j.immuni.2013.02.010

22. Monticelli LA, Sonnenberg GF, Abt MC, Alenghat T, Ziegler CG, Doering TA, et al. Innate Lymphoid Cells Promote Lung-Tissue Homeostasis After
Infection With Influenza Virus. Nat Immunol (2011) 12(11):1045-54. doi: $10.1031 /$ ni.2131

23. Wilhelm C, Hirota K, Stieglitz B, Van Snick J, Tolaini M, Lahl K, et al. An IL-9 Fate Reporter Demonstrates the Induction of an Innate IL-9 Response in Lung Inflammation. Nat Immunol (2011) 12(11):1071-7. doi: 10.1038/ni.2133

24. Lo BC, Canals Hernaez D, Scott RW, Hughes MR, Shin SB, Underhill TM, et al. The Transcription Factor RORalpha Preserves ILC3 Lineage Identity and Function During Chronic Intestinal Infection. J Immunol (2019) 203 (12):3209-15. doi: 10.4049/jimmunol.1900781

25. Zhou W, Sonnenberg GF. Activation and Suppression of Group 3 Innate Lymphoid Cells in the Gut. Trends Immunol (2020) 41(8):721-33. doi: 10.1016/j.it.2020.06.009

26. Cherrier M, Eberl G. The Development of LTi Cells. Curr Opin Immunol (2012) 24(2):178-83. doi: 10.1016/j.coi.2012.02.003

27. Halim TY, Steer CA, Matha L, Gold MJ, Martinez-Gonzalez I, McNagny KM, et al. Group 2 Innate Lymphoid Cells are Critical for the Initiation of Adaptive T Helper 2 Cell-Mediated Allergic Lung Inflammation. Immunity (2014) 40 (3):425-35. doi: 10.1016/j.immuni.2014.01.011

28. Moro K, Yamada T, Tanabe M, Takeuchi T, Ikawa T, Kawamoto H, et al. Innate Production of $\mathrm{T}(\mathrm{H}) 2$ Cytokines by Adipose Tissue-Associated c-Kit(+) Sca-1(+) Lymphoid Cells. Nature (2010) 463(7280):540-4. doi: 10.1038/ nature 08636

29. Yang Q, Li F, Harly C, Xing S, Ye L, Xia X, et al. TCF-1 Upregulation Identifies Early Innate Lymphoid Progenitors in the Bone Marrow. Nat Immunol (2015) 16(10):1044-50. doi: 10.1038/ni.3248

30. Klose CSN, Flach M, Mohle L, Rogell L, Hoyler T, Ebert K, et al. Differentiation of Type 1 ILCs From a Common Progenitor to All HelperLike Innate Lymphoid Cell Lineages. Cell (2014) 157(2):340-56. doi: 10.1016/ j.cell.2014.03.030

31. Possot C, Schmutz S, Chea S, Boucontet L, Louise A, Cumano A, et al. Notch Signaling is Necessary for Adult, But Not Fetal, Development of RORgammat (+) Innate Lymphoid Cells. Nat Immunol (2011) 12(10):949-58. doi: 10.1038/ ni. 2105

32. Yu X, Wang Y, Deng M, Li Y, Ruhn KA, Zhang CC, et al. The Basic Leucine Zipper Transcription Factor NFIL3 Directs the Development of a Common Innate Lymphoid Cell Precursor. Elife (2014) 3:e04406. doi: 10.7554/ eLife.04406

33. Xu W, Domingues RG, Fonseca-Pereira D, Ferreira M, Ribeiro H, LopezLastra S, et al. NFIL3 Orchestrates the Emergence of Common Helper Innate Lymphoid Cell Precursors. Cell Rep (2015) 10(12):2043-54. doi: 10.1016/ j.celrep.2015.02.057

34. Seillet C, Rankin LC, Groom JR, Mielke LA, Tellier J, Chopin M, et al. Nfil3 is Required for the Development of All Innate Lymphoid Cell Subsets. J Exp Med (2014) 211(9):1733-40. doi: 10.1084/jem.20140145

35. Jones R, Cosway EJ, Willis C, White AJ, Jenkinson WE, Fehling HJ, et al. Dynamic Changes in Intrathymic ILC Populations During Murine Neonatal Development. Eur J Immunol (2018) 48(9):1481-91. doi: 10.1002/ eji.201847511

36. Ferreira ACF, Szeto ACH, Heycock MWD, Clark PA, Walker JA, Crisp A, et al. Roralpha is a Critical Checkpoint for T Cell and ILC2 Commitment in the Embryonic Thymus. Nat Immunol (2021) 22(2):166-78. doi: 10.1038/ s41590-020-00833-w

37. Yang Q, Bhandoola A. The Development of Adult Innate Lymphoid Cells. Curr Opin Immunol (2016) 39:114-20. doi: 10.1016/j.coi.2016.01.006

38. Koga S, Hozumi K, Hirano KI, Yazawa M, Terooatea T, Minoda A, et al. Peripheral PDGFRalpha(+)gp38(+) Mesenchymal Cells Support the Differentiation of Fetal Liver-Derived ILC2. J Exp Med (2018) 215(6):160926. doi: 10.1084/jem.20172310

39. Cumano A, Berthault C, Ramond C, Petit M, Golub R, Bandeira A, et al. New Molecular Insights Into Immune Cell Development. Annu Rev Immunol (2019) 37:497-519. doi: 10.1146/annurev-immunol-042718-041319

40. Chea S, Schmutz S, Berthault C, Perchet T, Petit M, Burlen-Defranoux O, et al. Single-Cell Gene Expression Analyses Reveal Heterogeneous Responsiveness of Fetal Innate Lymphoid Progenitors to Notch Signaling. Cell Rep (2016) 14 (6):1500-16. doi: 10.1016/j.celrep.2016.01.015

41. Bando JK, Liang HE, Locksley RM. Identification and Distribution of Developing Innate Lymphoid Cells in the Fetal Mouse Intestine. Nat Immunol (2015) 16(2):153-60. doi: 10.1038/ni.3057 
42. Sawa S, Lochner M, Satoh-Takayama N, Dulauroy S, Berard M, Kleinschek M, et al. Rorgammat+ Innate Lymphoid Cells Regulate Intestinal Homeostasis by Integrating Negative Signals From the Symbiotic Microbiota. Nat Immunol (2011) 12(4):320-6. doi: 10.1038/ni.2002

43. Tang Y, Peitzsch C, Charoudeh HN, Cheng M, Chaves P, Jacobsen SE, et al. Emergence of NK-cell Progenitors and Functionally Competent NK-cell Lineage Subsets in the Early Mouse Embryo. Blood (2012) 120(1):63-75. doi: 10.1182/blood-2011-02-337980

44. Bai L, Vienne M, Tang L, Kerdiles Y, Etiennot M, Escaliere B, et al. Liver Type 1 Innate Lymphoid Cells Develop Locally Via an Interferon-GammaDependent Loop. Science (2021) 371(6536):eaba4177. doi: 10.1126/ science.aba4177

45. Gasteiger G, Fan X, Dikiy S, Lee SY, Rudensky AY. Tissue Residency of Innate Lymphoid Cells in Lymphoid and Nonlymphoid Organs. Science (2015) 350 (6263):981-5. doi: 10.1126/science.aac9593

46. Moro K, Kabata H, Tanabe M, Koga S, Takeno N, Mochizuki M, et al. Interferon and IL-27 Antagonize the Function of Group 2 Innate Lymphoid Cells and Type 2 Innate Immune Responses. Nat Immunol (2016) 17(1):7686. doi: 10.1038/ni.3309

47. Schneider C, Lee J, Koga S, Ricardo-Gonzalez RR, Nussbaum JC, Smith LK, et al. Tissue-Resident Group 2 Innate Lymphoid Cells Differentiate by Layered Ontogeny and In Situ Perinatal Priming. Immunity (2019) 50(6):1425-38.e5. doi: 10.1016/j.immuni.2019.04.019

48. Ghaedi M, Shen ZY, Orangi M, Martinez-Gonzalez I, Wei L, Lu X, et al. Single-Cell Analysis of RORalpha Tracer Mouse Lung Reveals ILC Progenitors and Effector ILC2 Subsets. J Exp Med (2020) 217(3):e20182293. doi: $10.1084 / \mathrm{jem} .20182293$

49. Koch U, Radtke F. Mechanisms of T Cell Development and Transformation. Annu Rev Cell Dev Biol (2011) 27:539-62. doi: 10.1146/annurev-cellbio092910-154008

50. Adolfsson J, Mansson R, Buza-Vidas N, Hultquist A, Liuba K, Jensen CT, et al. Identification of Flt3+ Lympho-Myeloid Stem Cells Lacking ErythroMegakaryocytic Potential a Revised Road Map for Adult Blood Lineage Commitment. Cell (2005) 121(2):295-306. doi: 10.1016/j.cell.2005.02.013

51. Lai AY, Kondo M. Asymmetrical Lymphoid and Myeloid Lineage Commitment in Multipotent Hematopoietic Progenitors. J Exp Med (2006) 203(8):1867-73. doi: 10.1084/jem.20060697

52. Bell JJ, Bhandoola A. The Earliest Thymic Progenitors for T Cells Possess Myeloid Lineage Potential. Nature (2008) 452(7188):764-7. doi: 10.1038/ nature 06840

53. Ciofani M, Zuniga-Pflucker JC. Determining Gammadelta Versus Alphass T Cell Development. Nat Rev Immunol (2010) 10(9):657-63. doi: 10.1038/ nri2820

54. Shah DK, Zuniga-Pflucker JC. An Overview of the Intrathymic Intricacies of $\mathrm{T}$ Cell Development. J Immunol (2014) 192(9):4017-23. doi: 10.4049/ jimmunol.1302259

55. Rothenberg EV, Moore JE, Yui MA. Launching the T-cell-lineage Developmental Programme. Nat Rev Immunol (2008) 8(1):9-21. doi: 10.1038/nri2232

56. Bresnick EH, Hewitt KJ, Mehta C, Keles S, Paulson RF, Johnson KD. Mechanisms of Erythrocyte Development and Regeneration: Implications for Regenerative Medicine and Beyond. Development (2018) 145(1): dev151423. doi: 10.1242/dev.151423

57. Hashimoto D, Chow A, Noizat C, Teo P, Beasley MB, Leboeuf M, et al. TissueResident Macrophages Self-Maintain Locally Throughout Adult Life With Minimal Contribution From Circulating Monocytes. Immunity (2013) 38 (4):792-804. doi: 10.1016/j.immuni.2013.04.004

58. Xiong N, Raulet DH. Development and Selection of Gammadelta T Cells. Immunol Rev (2007) 215:15-31. doi: 10.1111/j.1600-065X.2006.00478.X

59. Spidale NA, Frascoli M, Kang J. gammadeltaTCR-independent Origin of Neonatal Gammadelta T Cells Prewired for IL-17 Production. Curr Opin Immunol (2019) 58:60-7. doi: 10.1016/j.coi.2019.04.011

60. Li Z, Liu S, Xu J, Zhang X, Han D, Liu J, et al. Adult Connective TissueResident Mast Cells Originate From Late Erythro-Myeloid Progenitors. Immunity (2018) 49(4):640-53.e5. doi: 10.1016/j.immuni.2018.09.023

61. Elsaid R, Soares-da-Silva F, Peixoto M, Amiri D, Mackowski N, Pereira P, et al. Hematopoiesis: A Layered Organization Across Chordate Species. Front Cell Dev Biol (2020) 8:606642. doi: 10.3389/fcell.2020.606642
62. Constantinides MG, McDonald BD, Verhoef PA, Bendelac A. A Committed Precursor to Innate Lymphoid Cells. Nature (2014) 508(7496):397-401. doi: 10.1038/nature13047

63. Harly C, Cam M, Kaye J, Bhandoola A. Development and Differentiation of Early Innate Lymphoid Progenitors. J Exp Med (2018) 215(1):249-62. doi: $10.1084 /$ jem.20170832

64. Shin SB, Lo BC, Ghaedi M, Scott RW, Li Y, Messing M, et al. Abortive gammadeltaTCR Rearrangements Suggest ILC2s are Derived From T-cell Precursors. Blood Adv (2020) 4(21):5362-72. doi: 10.1182/bloodadvances. 2020002758

65. Veinotte LL, Greenwood CP, Mohammadi N, Parachoniak CA, Takei F. Expression of Rearranged TCRgamma Genes in Natural Killer Cells Suggests a Minor Thymus-Dependent Pathway of Lineage Commitment. Blood (2006) 107(7):2673-9. doi: 10.1182/blood-2005-07-2797

66. Mazzurana L, Czarnewski P, Jonsson V, Wigge L, Ringner M, Williams TC, et al. Tissue-Specific Transcriptional Imprinting and Heterogeneity in Human Innate Lymphoid Cells Revealed by Full-Length Single-Cell RNA-Sequencing. Cell Res (2021). doi: 10.1038/s41422-020-00445-x

67. Morgan TH. The Theory of the Gene. etc., New Haven: Yale University Press (1926).

68. Maillard I, Fang T, Pear WS. Regulation of Lymphoid Development, Differentiation, and Function by the Notch Pathway. Annu Rev Immunol (2005) 23:945-74. doi: 10.1146/annurev.immunol.23.021704.115747

69. Hosokawa H, Rothenberg EV. How Transcription Factors Drive Choice of the T Cell Fate. Nat Rev Immunol (2021) 21(3):162-76. doi: 10.1038/s41577-02000426-6

70. Radtke F, Wilson A, MacDonald HR. Notch Signaling in T- and B-cell Development. Curr Opin Immunol (2004) 16(2):174-9. doi: 10.1016/ j.coi.2004.01.002

71. Georgiades P, Ogilvy S, Duval H, Licence DR, Charnock-Jones DS, Smith SK, et al. VavCre Transgenic Mice: A Tool for Mutagenesis in Hematopoietic and Endothelial Lineages. Genesis (2002) 34(4):251-6. doi: 10.1002/gene.10161

72. Lee JS, Cella M, McDonald KG, Garlanda C, Kennedy GD, Nukaya M, et al. AHR Drives the Development of Gut ILC22 Cells and Postnatal Lymphoid Tissues Via Pathways Dependent on and Independent of Notch. Nat Immunol (2011) 13(2):144-51. doi: 10.1038/ni.2187

73. Seehus CR, Aliahmad P, de la Torre B, Iliev ID, Spurka L, Funari VA, et al. The Development of Innate Lymphoid Cells Requires TOX-dependent Generation of a Common Innate Lymphoid Cell Progenitor. Nat Immunol (2015) 16 (6):599-608. doi: 10.1038/ni.3168

74. Rothenberg EV, Ungerback J, Champhekar A. Forging T-Lymphocyte Identity: Intersecting Networks of Transcriptional Control. Adv Immunol (2016) 129:109-74. doi: 10.1016/bs.ai.2015.09.002

75. Rothenberg EV. Single-Cell Insights Into the Hematopoietic Generation of Tlymphocyte Precursors in Mouse and Human. Exp Hematol (2021) 95:1-12. doi: 10.1016/j.exphem.2020.12.005

76. Miyazaki M, Miyazaki K, Chen K, Jin Y, Turner J, Moore AJ, et al. The E-Id Protein Axis Specifies Adaptive Lymphoid Cell Identity and Suppresses Thymic Innate Lymphoid Cell Development. Immunity (2017) 46(5):81834.e4. doi: 10.1016/j.immuni.2017.04.022

77. Califano D, Cho JJ, Uddin MN, Lorentsen KJ, Yang Q, Bhandoola A, et al. Transcription Factor Bcl11b Controls Identity and Function of Mature Type 2 Innate Lymphoid Cells. Immunity (2015) 43(2):354-68. doi: 10.1016/ j.immuni.2015.07.005

78. Hosokawa H, Romero-Wolf M, Yang Q, Motomura Y, Levanon D, Groner Y, et al. Cell Type-Specific Actions of Bcl11b in Early T-lineage and Group 2 Innate Lymphoid Cells. J Exp Med (2020) 217(1):e20190972. doi: 10.1084/jem.20190972

79. Wang HC, Qian L, Zhao Y, Mengarelli J, Adrianto I, Montgomery CG, et al. Downregulation of E Protein Activity Augments an ILC2 Differentiation Program in the Thymus. J Immunol (2017) 198(8):3149-56. doi: 10.4049/ jimmunol.1602009

80. Qian L, Bajana S, Georgescu C, Peng V, Wang HC, Adrianto I, et al. Suppression of ILC2 Differentiation From Committed T Cell Precursors by E Protein Transcription Factors. J Exp Med (2019) 216(4):884-99. doi: $10.1084 /$ jem. 20182100

81. Kominami R. Role of the Transcription Factor Bcl11b in Development and Lymphomagenesis. Proc Jpn Acad Ser B Phys Biol Sci (2012) 88(3):72-87. doi: $10.2183 /$ pjab.88.72 
82. Li P, Burke S, Wang J, Chen X, Ortiz M, Lee SC, et al. Reprogramming of T Cells to Natural Killer-Like Cells Upon Bcl11b Deletion. Science (2010) 329 (5987):85-9. doi: 10.1126/science.1188063

83. Li L, Leid M, Rothenberg EV. An Early T Cell Lineage Commitment Checkpoint Dependent on the Transcription Factor Bcl11b. Science (2010) 329(5987):89-93. doi: 10.1126/science.1188989

84. Yu Y, Wang C, Clare S, Wang J, Lee SC, Brandt C, et al. The Transcription Factor Bcl11b is Specifically Expressed in Group 2 Innate Lymphoid Cells and is Essential for Their Development. J Exp Med (2015) 212(6):865-74. doi: $10.1084 /$ jem. 20142318

85. Bando JK, Colonna M. Innate Lymphoid Cell Function in the Context of Adaptive Immunity. Nat Immunol (2016) 17(7):783-9. doi: 10.1038/ni.3484

86. Laurent J, Bosco N, Marche PN, Ceredig R. New Insights Into the Proliferation and Differentiation of Early Mouse Thymocytes. Int Immunol (2004) 16(8):1069-80. doi: 10.1093/intimm/dxh108

87. Shinkai Y, Rathbun G, Lam KP, Oltz EM, Stewart V, Mendelsohn M, et al. Rag-2-deficient Mice Lack Mature Lymphocytes Owing to Inability to Initiate V(D)J Rearrangement. Cell (1992) 68(5):855-67. doi: 10.1016/0092-8674(92) 90029-c

88. Mombaerts P, Iacomini J, Johnson RS, Herrup K, Tonegawa S, Papaioannou VE. Rag-1-deficient Mice Have No Mature B and T Lymphocytes. Cell (1992) 68(5):869-77. doi: 10.1016/0092-8674(92)90030-g

89. Diamond RA, Ward SB, Owada-Makabe K, Wang H, Rothenberg EV. Different Developmental Arrest Points in RAG-2 -/- and SCID Thymocytes on Two Genetic Backgrounds: Developmental Choices and Cell Death Mechanisms Before TCR Gene Rearrangement. J Immunol (1997) 158 (9):4052-64.

90. Vaidya HJ, Briones Leon A, Blackburn CC. FOXN1 in Thymus Organogenesis and Development. Eur J Immunol (2016) 46(8):1826-37. doi: 10.1002/ eji.201545814

91. Roediger B, Kyle R, Yip KH, Sumaria N, Guy TV, Kim BS, et al. Cutaneous Immunosurveillance and Regulation of Inflammation by Group 2 Innate Lymphoid Cells. Nat Immunol (2013) 14(6):564-73. doi: $10.1038 /$ ni.2584

92. Wong SH, Walker JA, Jolin HE, Drynan LF, Hams E, Camelo A, et al. Transcription Factor RORalpha is Critical for Nuocyte Development. Nat Immunol (2012) 13(3):229-36. doi: 10.1038/ni.2208
93. Zeis P, Lian M, Fan X, Herman JS, Hernandez DC, Gentek R, et al. In Situ Maturation and Tissue Adaptation of Type 2 Innate Lymphoid Cell Progenitors. Immunity (2020) 53(4):775-92.e9. doi: $10.1016 /$ j.immuni.2020.09.002

94. Huang Y, Mao K, Chen X, Sun MA, Kawabe T, Li W, et al. S1P-Dependent Interorgan Trafficking of Group 2 Innate Lymphoid Cells Supports Host Defense. Science (2018) 359(6371):114-9. doi: 10.1126/science.aam5809

95. Teitelbaum SL, Ross FP. Genetic Regulation of Osteoclast Development and Function. Nat Rev Genet (2003) 4(8):638-49. doi: 10.1038/nrg1122

96. Khodadadi L, Cheng Q, Radbruch A, Hiepe F. The Maintenance of Memory Plasma Cells. Front Immunol (2019) 10:721. doi: 10.3389/fimmu.2019.00721

97. Riedel R, Addo R, Ferreira-Gomes M, Heinz GA, Heinrich F, Kummer J, et al. Discrete Populations of Isotype-Switched Memory B Lymphocytes are Maintained in Murine Spleen and Bone Marrow. Nat Commun (2020) 11 (1):2570. doi: 10.1038/s41467-020-16464-6

98. Boberg E, Johansson K, Malmhall C, Calven J, Weidner J, Radinger M. Interplay Between the IL-33/ST2 Axis and Bone Marrow ILC2s in Protease Allergen-Induced IL-5-Dependent Eosinophilia. Front Immunol (2020) 11:1058. doi: 10.3389/fimmu.2020.01058

99. Boberg E, Johansson K, Malmhall C, Weidner J, Radinger M. House Dust Mite Induces Bone Marrow Il-33-Responsive ILC2s and TH Cells. Int J Mol Sci (2020) 21(11):3751. doi: 10.3390/ijms21113751

100. Sudo T, Motomura Y, Okuzaki D, Hasegawa T, Yokota T, Kikuta J, et al. Group 2 Innate Lymphoid Cells Support Hematopoietic Recovery Under Stress Conditions. J Exp Med (2021) 218(5):e20200817. doi: 10.1084/ jem.20200817

Conflict of Interest: The authors declare that the research was conducted in the absence of any commercial or financial relationships that could be construed as a potential conflict of interest.

Copyright $\odot 2021$ Shin and McNagny. This is an open-access article distributed under the terms of the Creative Commons Attribution License (CC BY). The use, distribution or reproduction in other forums is permitted, provided the original author(s) and the copyright owner(s) are credited and that the original publication in this journal is cited, in accordance with accepted academic practice. No use, distribution or reproduction is permitted which does not comply with these terms. 